\title{
Biodiversity of Glomus species in the Rhizosphere of Some Ornamental Plants of Family Asteraceae
}

\author{
Malvika Shekhar* and Monica Basu \\ Department of Botany, University of Allahabad, Allahabad 211002, Uttar Pradesh, India \\ *Corresponding author
}

\begin{tabular}{|c|c|}
\hline & \multirow{6}{*}{$\begin{array}{l}\text { A B S T R A C T } \\
\text { In India, cut flowers are highly demanded due to their uses in religious and } \\
\text { aesthetic purposes. Natural VA mycorrhizal associations in plants are } \\
\text { highly beneficial. Thus, it is very essential to characterize the biodiversity } \\
\text { of VAM fungi in plants of economical significance. VAM spores are } \\
\text { differentiated in the rhizosphere and act as a reference structure for species } \\
\text { identification of these fungi. Spores of species of Glomus exhibit the most } \\
\text { diverse morphology in family Glomaceae. In the present study, the } \\
\text { rhizospheric soils of some ornamental plants belonging to family } \\
\text { Asteraceae were screened. Seven species of Glomus were isolated and } \\
\text { identified during the investigation. }\end{array}$} \\
\hline Keywords & \\
\hline & \\
\hline & \\
\hline & \\
\hline & \\
\hline
\end{tabular}

\section{Introduction}

Flowers have been the symbols of nature, beauty and love. In India, they are commonly used for religious purposes and they play an important role as décor items in weddings and festival occasions. Flowers are very important for their economic uses, such as, for cut blooms and for extraction of perfumes. Besides this, the seed and nursery business and export of the ornamental plants, seeds and bulbs are progressing every year. Some of the flowering ornamentals have medicinal value such as some species of calendula, tagetus, and chrysanthemums etc.

In India, Floricultural units have increased the export of Floricultural products and enabled the country to become small but important player in the world market. Inspite of this, India's share in the international market for these flowers is negligible due to inadequate research support. Therefore, Floriculture should be treated as agriculture instead of considering it as an industry and it requires much research work to improve the quality as well as quantity of floricultural products, by using VAM fungi as a potential biofertilizer. This needs extensive survey and study of the native VAM fungal composition for the selection of most appropriate and most efficient VAM fungal species as an inoculum, for a particular floricultural crop.

VA mycorrhizae are associated with almost all plants in nature (Hayman, 1982). They 
become established in plant root cortical cells by forming hyphae, arbuscules and vesicles. There is bidirectional movement of nutrients between the fungus and the plant roots and thus their association is highly beneficial for the host plant. VAM fungal spores are produced in rhizosphere as well as roots. Spores can survive in the soil for a long time and they serve as fungal propagules. They also act as reference structure for species identification of VAM fungi. The morphological characteristics of spores are mainly used to taxonomically identify the respective fungal species.

Among all the genera of VAM fungi, Glomus is the largest and most commonly occurring genus. It may form an endosymbiotic relationship with $70-90 \%$ of extant vascular plants. Spores of species of Glomus exhibit the most diverse morphology in family Glomaceae. Glomus is the most important mycorrhizal fungus for increasing the biomass of crop plants, in agriculture and forest management.

The Glomus-plant symbiosis plays an important role in the economic sectors involving the growth of plants such as agriculture, horticulture, and forestry. As a fungi, Glomus, contributes to fungal biomass dominance of soils.

It is essential to characterize the biodiversity of VAM fungi in plants of economical significance. In recent years, the needs for indigenous VAM species isolation, screening and identification have been emphasized for their practical and applied aspects. With this objective, this investigation was conducted to isolate and identify the species of Glomus in the rhizospheric soils of some ornamentals plants of family Asteraceae. Asteraceae is one of the important families of ornamental flowering plants and some species are also of medicinal value.

\section{Materials and Methods}

Soil samples were collected from the rhizospheres of the selected ornamental plants of family Asteraceae (Calendula officinalis, Chrysanthemum indicum and Tagetus erecta) from different sites of Allahabad (Uttar Pradesh). Rhizospheric soils at a depth of 4$16 \mathrm{~cm}$ were collected in sterile polythene bags using soil auger. Spores of VAM fungi were extracted from the soil by wet sieving and decanting technique (Gerdemann and Nicolson, 1963). For taxonomic purpose, spores were mounted in PVLG medium.

\section{Results and Discussion}

Seven species of the genus Glomus were isolated and identified by using manuals of Trappe (1982), Morton and Benny (1990), Walker (1983), Schenck and Perez (1990) and Mukerji (1996).

\section{Glomus}

Spores are borne terminally on a single undifferentiated hypha; spores attached with one or more subtending hyphae; spores produced singly or in loose or tight aggregates or in sporocarps in soil. The spores are formed at the end of hyphae which may be constricted at the point of attachment to the spore. The spore wall can have one to many layers, without ornamentation.

The taxonomy of spores of Glomus species that encountered during this survey is as under:

\section{Glomus caledonium (Nicol. and Gerd.) Trappe and Gerdemann}

Spores borne singly in soil, yellow to brown, globose to subglobose, $67-154 \mu \mathrm{m} \times 73$ $154 \mu \mathrm{m}$, with only one but occasionally two distinct funnel-shaped subtending hyphae. 
Spore tapering towards hyphal attachment. Spore wall structure consists of two walls (Walls 1 and 2) in a single group. Wall 1 outermost, thin, subhyaline, unit wall. Wall 2 innermost, thicker than outer wall, yellowishbrown and laminated. Subtending hypha curved, single, funnel-shaped, $30 \mu \mathrm{m}$ wide at the point of spore attachment, hyphal pore closed by a septum, hyphal wall yellow, outer wall hyaline and inner wall yellow.

Description based on the spore isolated from the rhizospheric soil of Calendula officinalis L.

\section{Glomus constrictum Trappe}

Spores are formed singly in soil, globose to subglobose, $88-114 \mu \mathrm{m}$ x $92-139 \mu \mathrm{m}$, pale brown and smooth. Spore wall structure consists of a single or occasionally appear two walled structure in a single group; composite wall thickness $7-10 \mu \mathrm{m}$. Subtending hyphae are curved, yellowish-brown, the hypha is constricted to $8-9 \mu \mathrm{m}$ just beyond the point of attachment and beyond the constriction, the hypha inflated upto $15-18 \mu \mathrm{m}$, hyphal wall yellow to yellow-brown in colour. Hyphal pore open.
Description based on spores isolated from rhizospheric soil of Calendula officinalis L. and Tagetus erecta Linn.

\section{Glomus maculosum Miller and Walker}

Spores formed singly in soil, globose to subglobose, yellowish-brown, $137 \mu \mathrm{m}$ in diameter with maculose or spotted ornamentation. Spore wall structure consists of three walls (walls 1-3) in two wall groups (wall group A and B). Wall group A consists of wall 1 and 2 together. Wall 1 hyaline, thin, unit wall and tightly adherent to wall 2 . Wall 2 brittle, yellowish-brown, laminated.

Wall group B consists of single, innermost, membranous, a very thin wall 3 , yellowishbrown; spores covered by dome-shaped outgrowths or spots of $6-10 \mu \mathrm{m}$ in diameter and up to $12 \mu \mathrm{m}$ deep; walls did not react with Melzer's reagent. Subtending hypha concolourous with spore wall 2, sharply recurved, parallel-sided, slightly constricted at the spore base, 5-6 $\mu \mathrm{m}$ wide at a point of attachment to spore.

Description based on the spores isolated from rhizospheric soil of Tagetus erecta Linn.

Fig.1 A spore of G. caledonium with funnel-shaped subtending hypha and showing a scar. Fig.2 Another spore of G. caledonium with subtending hypha
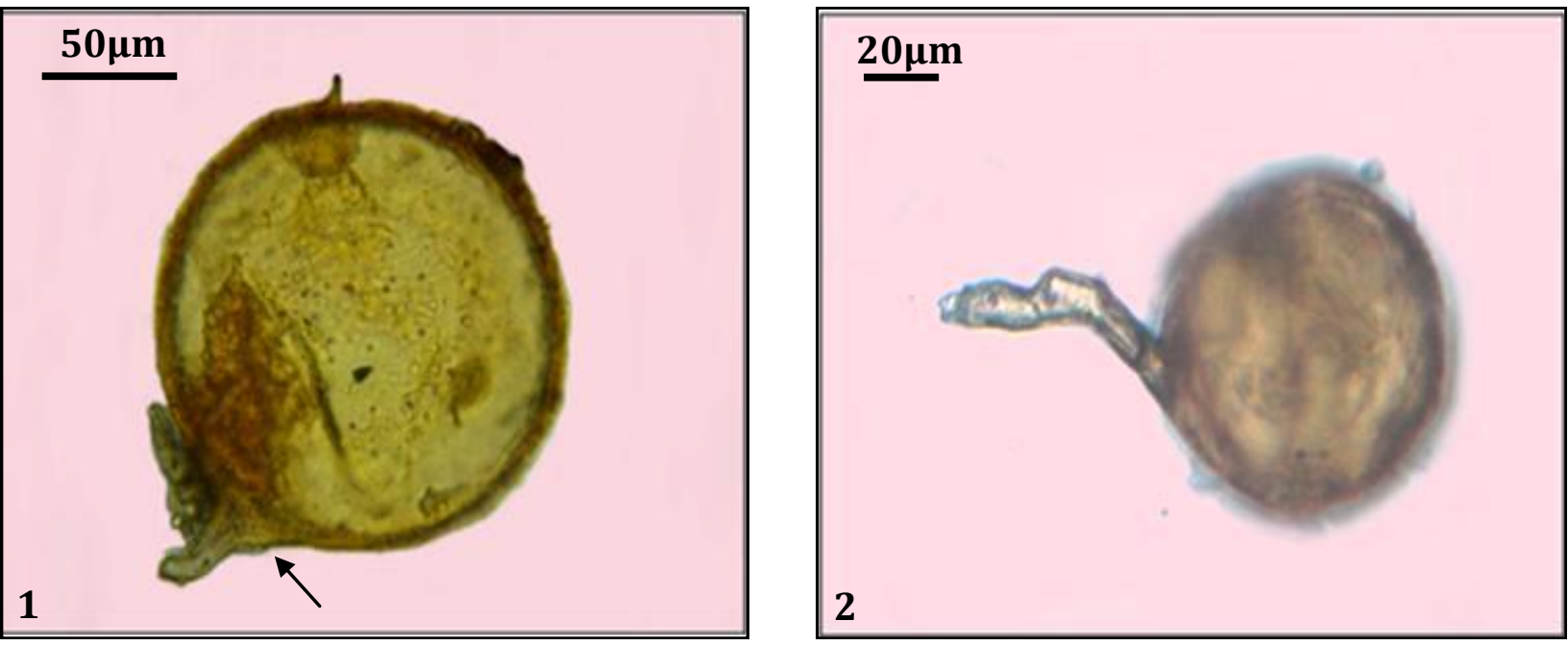
Fig.3 A spore of G. constrictum showing constricted subtending hypha. Fig.4 Spore of $G$. constrictum showing recurved and constricted subtending hypha
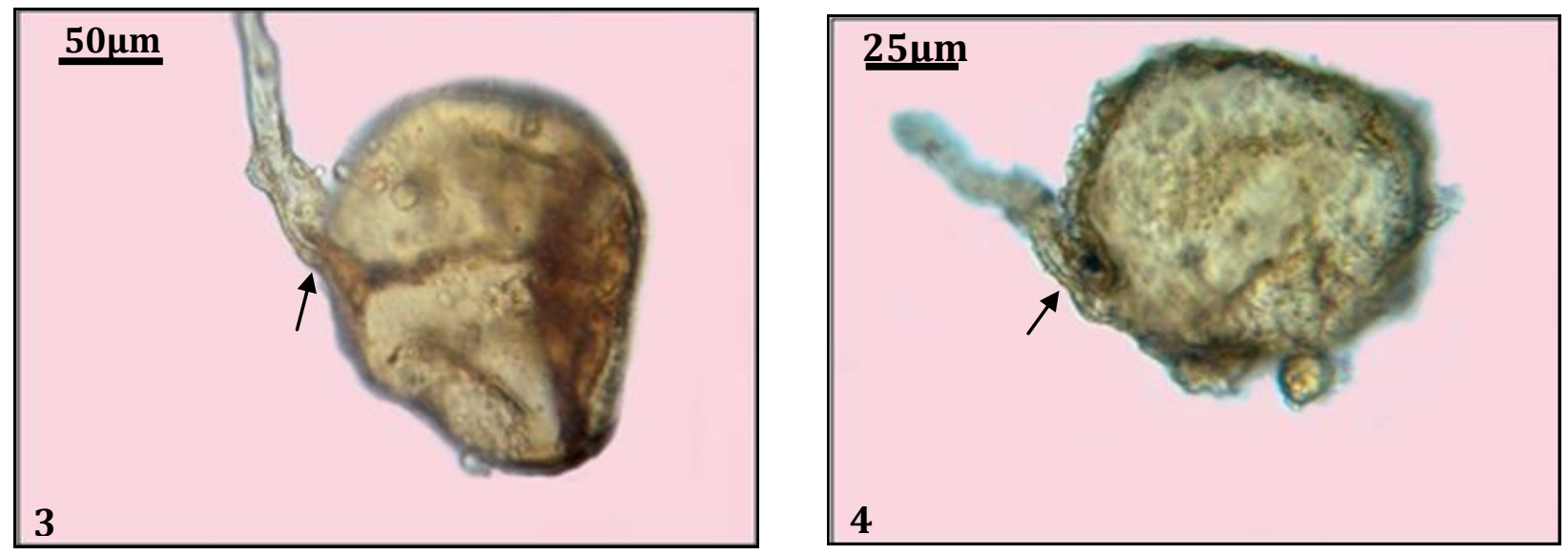

Fig.5 A spore of G. maculosum having spotted ornamentation. Fig.6 A spore of $G$. melanosporum with ephemeral hyaline subtending hypha
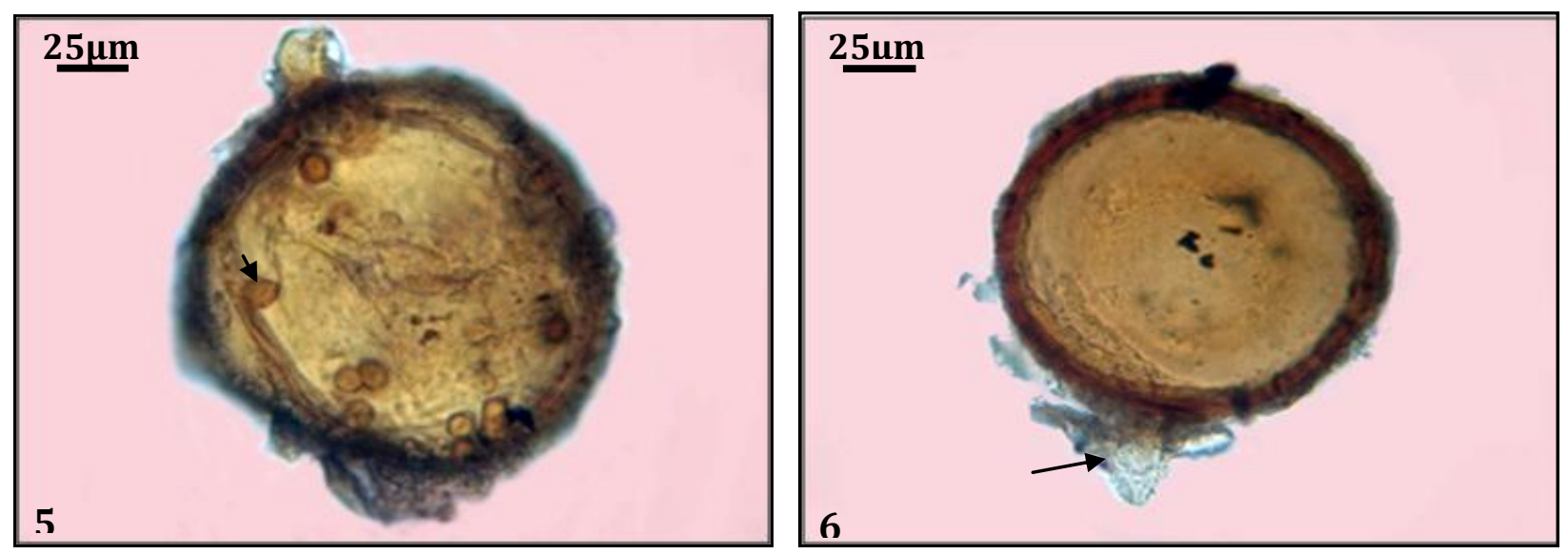

Fig.7 and 8 Clusters of spores of Glomus microaggregatum inside unidentified VAM fungal spores
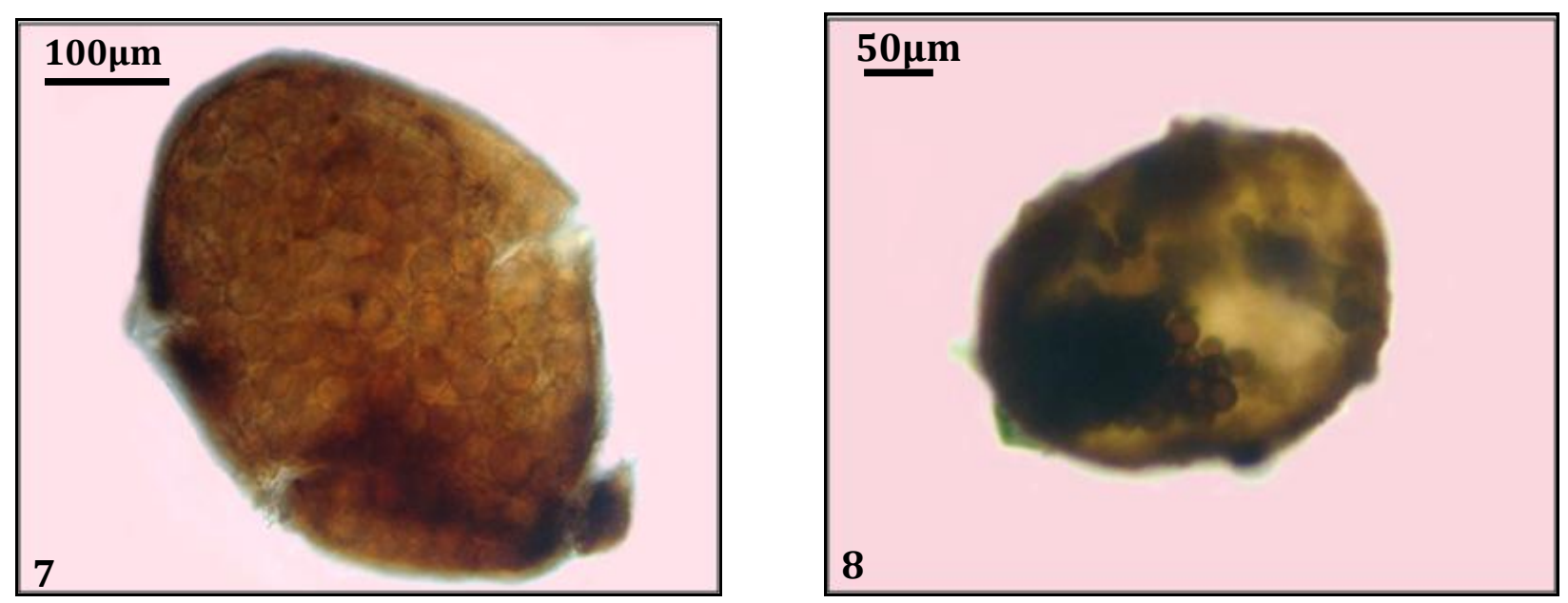
Fig.9 and 10 Spores of G. microaggregatum
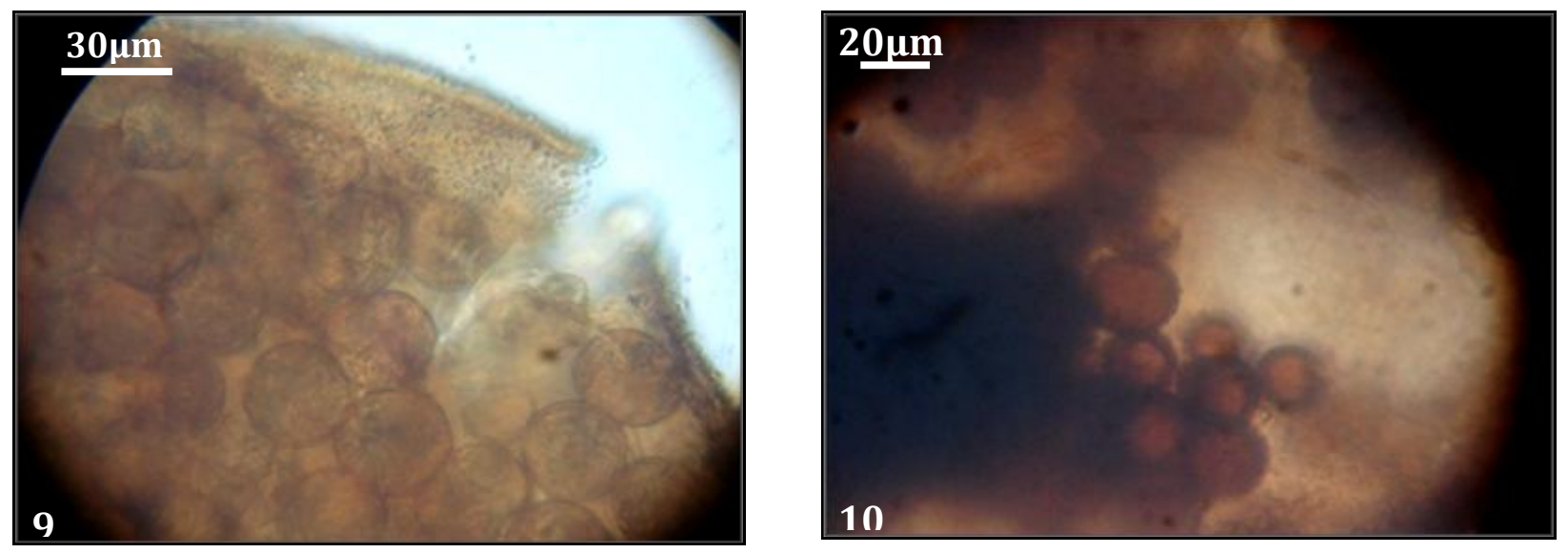

Fig.11 A spore of G. nanolumen showing very thick walls making the lumen narrow and somewhat triangular

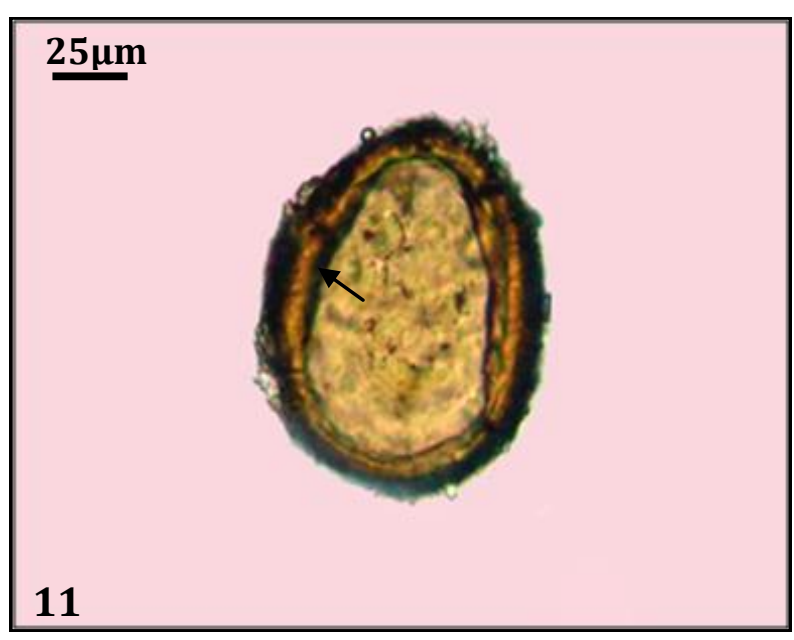

Fig.12 and 13 Spores of G. reticulatum
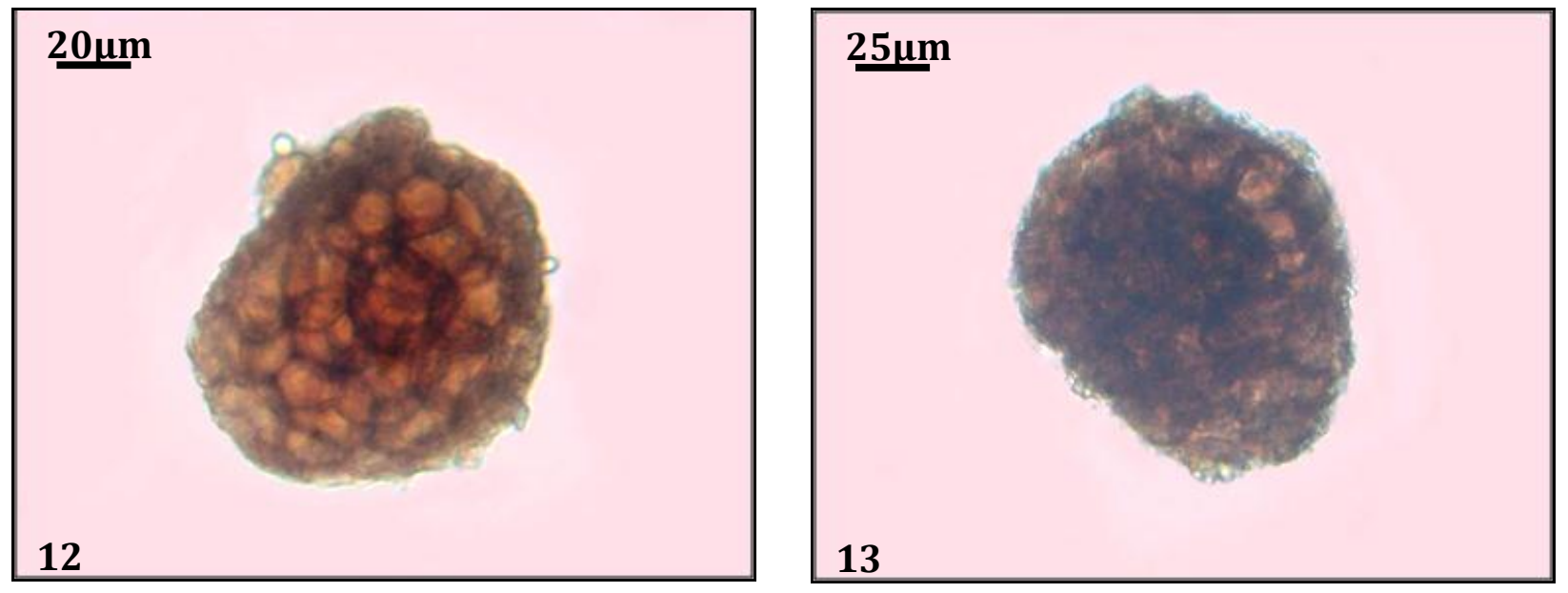
Glomus melanosporum Gerdemann and Trappe

Spores are formed singly in soil, globose to subglobose, light brown to dark brown, $114 \mu \mathrm{m} \times 126 \mu \mathrm{m}$ and smooth walled. Spore wall structure consists of a single wall, laminated, grading in colour from dark brown at the outer surface and light yellowish-brown inner surface. Subtending hypha 1-2, thin walled, hyaline to pale yellow, difficult to observe, wide at the point of spore attachment, curved, pore open or closed by spore wall septum.

Description based on the spores found in the rhizospheric soil of Calendula officinalis $\mathrm{L}$.

\section{Glomus microaggregatum Koske, Gemma and Olexia}

Spores formed singly in the soil or in clusters inside the dead spores of other members of VAM fungi, hyaline to pale yellow to brownish-yellow, globose to subglobose, 11$30 \mu \mathrm{m} \times 14-35 \mu \mathrm{m}$ in diameter. Spore wall structure consists of two walls (walls 1 and 2) in a single group. Wall 1 consists of smooth, brittle, unit, hyaline to pale brown. Wall 2 is membranous or unit wall, concolourous with wall 1 . Subtending hypha cylindrical, straight, 1.5-2.0 $\mu \mathrm{m}$ wide at the point of attachment, hyphal wall hyaline and up to $1.5 \mu \mathrm{m}$ thick, hyphal pore open but sometimes closed by a septum formed by wall 2 .

Description based on the spores isolated from rhizospheric soils of Chrysanthemum indicum L. and Tagetus erecta Linn. They were found within dead spores of other VAM fungal members.

\section{Glomus nanolumen Koske and Gemma}

Spores formed singly in soil, subglobose or pyriform ovoid, $100 \mu \mathrm{m} \times 110 \mu \mathrm{m}$, yellowish- brown, smooth-walled. Spore wall structure consists of a double wall (wall 1 and 2). Wall 1 shining yellow to yellowish-brown, $2-3 \mu \mathrm{m}$ thick, unit wall, adherent to wall 2, smooth. Wall 2 brown, laminated, very thick 10 $17 \mu \mathrm{m}$, making the lumen of the spore narrow. Subtending hypha not observed.

Description based on the spore isolated from rhizospheric soil of Calendula officinalis $\mathrm{L}$.

\section{Glomus reticulatum Bhattacharjee and Mukerji}

Spores are borne freely and singly in soil, globose to subglobose or ellipsoidal, dark brown to brownish black, 90-105 $\mu \mathrm{m} \times$ 96-134 $\mu \mathrm{m}$ having reticulate ornamentation. Spore wall structure consists of double wall (wall 1 and 2) in a single group. Wall 1 is yellowish brown, laminated and not fissured. Wall 2 is yellowish-brown to blackish-brown with regular geometric reticulate markings of 4$10 \mu \mathrm{m}$ apart. Subtending hyphae not observed.

Description based on the spores isolated from rhizospheric soil of Calendula officinalis $\mathrm{L}$. and Chrysanthemum indicum $\mathrm{L}$.

Earlier, some workers have reported various species of Glomus in the rhizosphere of different ornamental plants from different areas. Kumar et al., (2009) studied species diversity of Glomus in some medicinal plants of Himachal Pradesh. Sharma et al., (2008) also reported seven species of Glomus from the sunflower rhizosphere of Haryana. Kumar et al., (2012) reported eleven species of Glomus in fifteen ornamental plants from Solan, Himachal Pradesh; Mishra et al., (2016) reported thirty one species of Glomus from the rhizosphere of five ornamental plants from Allahabad. Shekhar and Basu (2017a) reported seven species of Glomus from the rhizosphere of Chrysanthemum indicum and Tagetus erecta and seven species 
from the rhizosphere of Helianthus annuиs (2017b) from Allahabad.

\section{Acknowledgement}

The authors are thankful to the Head, Department of Botany, University of Allahabad for providing necessary research facilities.

\section{References}

Gerdemann, J. W. and Nicolson, Y. H. 1963. Spores of mycorrhizae Endogone species extracted from soil by wet sieving and decanting. Trans. Br. Mycol. Soc. 46: 235-244.

Hayman, D. S. 1982. Practical Aspects of VAM. In: Advances in Agricultural Microbiology (ed. Subba Rao, N. S.), New Delhi Oxford, IBA, pp. 325-373.

Kumar, A., Bhatti, S. K. and Aggarwal, A. 2012. Biodiversity of Endophytic Mycorrhiza in some ornamental flowering plants of Solan, Himachal Pradesh. Biological Forum, 4(2): 45-51.

Kumar, A., Singh, S. and Pandey, A. 2009. Species diversity of the genus Glomus associated with some important medicinal plants. J. Indian Bot. Soc., 88(2): 80-86.

Mishra, R., Kehri, H. K. and Akhtar, O. 2016. Diversity and status of arbuscular mycorrhizal fungi in the ornamental plants growing under natural conditions at different sites of Allahabad. Journal of Basic and Applied Mycology, 12 (II): 64-76
Morton, J. B. and Benny, G. L. 1990. Revised classification of arbuscular mycorrhizal fungi (Zygomycetes): New order Glomales, two new sub-orders, Glomineae and Gigasporineae, and two new families, Acaulosporaceae and Gigasporaceae, with emendation of Glomaceae. Mycotaxon. 37: 471-491.

Mukerji, K. G. 1996. Taxonomy of endomycorrhizal fungi. In: Mukerji, K. G., Mathur, B., Chamola, B. P., and Chitralekha, P. $(E d s)$. Advances in Botany. APH Pub. Corp. New Delhi. Pp. 211-221.

Pirozynski, K. A. and Dalpe, Y. 1989. Geological Society of Glomaceae with particular reference to mycorrhizal symbiosis. Symbiosis. 7: 1-36

Schenck, N. C and Perez, Y. 1990. Manual for identification of VA mycorrhizal fungi. Univ of Florida Press, Florida, USA. pp. 241.

Sharma, S. V. Parkash, S. Kaushish and A. Aggarwal, 2008. A monograph of Glomus spp. (Glomaceae) in Sunflower Rhizosphere in Haryana, India. Helia, 32. $\operatorname{Nr}(50): 69-76$

Shekhar, M. and Basu, M. (2017a). Studies on Glomus species in the rhizosphere of some ornamental plants of family Asteraceae. Journal of Mycopathological Research, 55(3): 309311.

Walker, C. 1983. Taxonomic concepts in the Endogonaceae spore wall characteristics in species description. Mycotaxon. 18: $443-445$.

\section{How to cite this article:}

Malvika Shekhar and Monica Basu. 2017. Biodiversity of Glomus species in the Rhizosphere of Some Ornamental Plants of Family Asteraceae. Int.J.Curr.Microbiol.App.Sci. 6(11): 26032609. doi: https://doi.org/10.20546/ijcmas.2017.611.305 